\title{
Notas M arginales sobre el Centenario de la Reforma Universitaria y la CRES 2018
}

DOI: http://dx.doi.org/10.25087/resur5a6

\section{A ugusto Pérez Lindo ${ }^{1}$}

En junio de 1918 comenzó el movimiento que luego se conoció como la Reforma Universitaria en la Universidad Nacional de Córdoba. Con motivo del centenario de dicho evento fue elegida la ciudad de Córdoba para realizar la III Conferencia Regional de Educación Superior para A mérica Latina y el Caribe (CRES2018) en el 14 de junio de 2018. Asistieron a este encuentro más de diez mil personas. Estudiantes, profesores, investigadores, funcionarios universitarios de toda A mérica Latina estuvieron presentes. Las numerosas comunicaciones están siendo aún analizadas. En un marco pluralista se comunicaron ponencias sobre los más diversos temas con los más diversos enfoques.

Los reclamos estudiantiles en la Universidad Nacional de Córdoba en 1918 dieron lugar a varias iniciativas que marcaron la evolución de las universidades públicas latinoamericanas. He aquí las principales propuestas que surgieron del aquel movimiento:

- Participación de estudiantes y graduados en la elección de autoridades;

- Participación directa de los profesores en la elección de autoridades;

\footnotetext{
${ }^{1}$ Doctor en Filosofía. Profesor de diversas universidades argentinas, de la región y del ámbito internacional. Miembro del Consejo Consultivo Asesor de IUSUR. Co-director de RESUR. perezlindo@gmail.com
} 
- Renovación por concurso público de los profesores para evitar arbitrariedades;

- Creación de cátedras libres;

- Actualización de los planes de estudio conforme a la evolución de las ciencias;

- Rendición de cuenta de las autoridades universitarias por su actuación.

Con este abanico de iniciativas el movimiento se convirtió en una fuerza renovadora y merece el reconocimiento de las universidades actuales. La participación de estudiantes y graduados se institucionalizó mediante un sistema de co-gobierno con los claustros respectivos. Fue una innovación importante para las universidades de todo el mundo, sin olvidar que ya en la Edad Media varias universidades como la de Paris o Bolonia reconocieron también la participación estudiantil en al gunas decisiones.

A hora parece obvio que los profesores deben elegir sus autoridades, pero todavía en muchos lugares esto compete a los gobiernos de los países respectivos. La renovación por concurso del cuerpo de profesores también constituye un aporte significativo. En Gran Bretaña rigió hasta la década de 1980 el nombramiento a título vitalicio de los cargos profesorales. Con la intervención de M argaret Thatcher, secretaria de Educación, comenzó a abolirse este régimen buscando la selección por concurso de los profesores.

La creación de las cátedras libres fuepensada para evitar el anquilosamiento o monopolio de una enseñanza determinada también resulta importante hasta nuestros días. Esta alternativa tiende a favorecer la introducción de nuevos enfoques en cualquier disciplina. Y esto se vincula también con el propósito de impulsar la modernización de los planes de estudio de acuerdo con los avances científicos.

La "rendición de cuentas de las autoridades" se convirtió con el correr de los tiempos en el "control de gestión" y "auditoría" de las universidades públicas. También se asocia 
actualmente con los sistemas de evaluación institucional que se han difundido en todas partes.

La Reforma Universitaria que comenzó en Córdoba se fue extendiendo en otros países (Perú, Colombia, M éxico, Cuba, entre otros). Entonces se asoció con los movimientos anti-imperialistas, liberales revolucionarios y socialistas. Progresivamente se convirtió en un semillero de líderes políticos democráticos, reformistas o revolucionarios que tuvieron diversas trayectorias (el diputado socialista Alfredo Palacios, el presidente desarrollista Arturo Frondizi, el presidente radical Raúl A Ifonsín, en A rgentina; Haya de la Torre, creador de la A lianza Popular Revolucionaria A mericana, APRA, en Perú, Eliecer Gaitán,del Partido Liberal en Colombia, son algunos casos notorios)

Se asoció a la Reforma Universitaria en Argentina con los movimientos democratizadores y populares. Pero, paradojalmente los reformistas apoyaron la destitución del Presidente Radical Hipólito Yrigoyen en 1930 que fue reemplazado por un general fascista (U riburu). T ambién se opusieron al primer gobierno de Perón (1946-55) y se aliaron con los sectores conservadores para derrocarlo. No obstante, esto, conserva, casi como propiedad intelectual, el apelativo de "progresistas" y tienen una fuerte presencia en los gobiernos de universidades públicas en A rgentina.

En el Centenario de la Reforma de 1918 deberíamos ser cautos en la reproducción de un mito: que la Reforma fue un agente de transformación de las universidades y que el movimiento reformista siempre apoyó los procesos democratizadores. No logró convertirse en un verdadero agente de transformación académica porque se conservaron no solo las prácticas pedagógicas tradicionales (cursos magistrales, planes de estudios rígidos y mono disciplinarios) sino que además se introdujeron muy tardíamente las políticas de 
investigación en las universidades (que se iniciaron hacia 1970 y se generalizaron recién en la década de 1990 en A rgentina)

Respecto al apoyo de los movimientos democratizadores ya señalamos los enfrentamientos con dos presidentes legítimos y populares como Yrigoyen y Perón. En la actualidad, y esto ha sido notorio en la reunión de la CRES 2018, se vieron pocos signos de solidaridad con estudiantes universitarios de Venezuela y Nicaragua, que han sido asesinados o encarcelados por sus respectivos gobiernos.

Al mismo tiempo que debemos relativizar el impacto de la Reforma de 1918 en la renovación de las universidades latinoamericanas también debemos resaltar que algunas de sus propuestas siguen siendo válidas para superar prácticas obsoletas. En muchos casos el régimen de concursos para la renovación de profesores se ha convertido en un rito para conservar a los que detentan las cátedras. La propuesta de Cátedras Libres ha sido muy poco aprovechada y resistida por autoridades universitarias. La participación de los graduados en el gobierno universitario no ha servido para conectar a las universidades con el mercado profesional y las demandas sociales. Casi siempre ha servido para representar el punto de vista de los colegios profesionales o de alguna facción política.

El régimen del co-gobierno estudiantil tenía como propósito brindar a los estudiantes la posibilidad de control y de gestión de la universidad. En la mayoría de los casos los delegados estudiantiles y de graduados no se preocupan por aprender a congestionar las universidades públicas sino a operar en nombre de agrupaciones o partidos políticos contribuyendo a crear un sistema clientelístico de gobierno.

Relatar esto se vuelve políticamente incorrecto en medio de la celebración del Centenario de la Reforma. En Córdoba, durante la primera quincena de junio se multiplicaron los discursos celebratorios y panegíricos de la Reforma. Se ha construido sin 
duda un mito al cual se atribuyen efectos aún en países como Brasil donde las universidades no conocieron la difusión de dicho movimiento.

La Declaración de la CRES2018 presentada en la Asamblea de la III Conferencia Regional de Educación Superior en la ciudad de Córdoba (A rgentina) el 14 de junio de 2018 contiene una serie de principios ya presentados en reuniones anteriores y algunos análisis sobre las situaciones actuales sin una visión del futuro y de las estrategias posibles para asumirlo en las universidades.

En el marco de la M aestría en Gestión Universitaria de la Universidad $\mathrm{N}$ acional de M ar del Plata me tocó dirigir un módulo sobre Planeamiento y Gestión A cadémica el 5 y el 6 de julio de 2018. Propusimos a los alumnos (directivos, funcionarios, profesores, de universidades públicas y privadas de Argentina) analizar la Declaración de la CRES 2018 para buscar algunas inspiraciones para pensar la universidad futura.

Estos son los puntos salientes de una primera lectura y comentario por parte de los alumnos y del profesor:

- Se ratifican las declaraciones de las conferencias anteriores respecto a considerar el acceso a la Educación Superior como un derecho humano y como un bien público;

- Se reivindica la autonomía universitaria como una capacidad para ejercer un papel crítico y propositivo frente a la sociedad

- Se afirma que la ciencia, las tecnologías y las artes son un medio para la libertad y la igualdad sin discriminación de ningún tipo

- Se critica la falta de regulaciones para contener las intervenciones de empresas universitarias extranjeras; 
- Se critica también toda forma de mercantilización de la educación superior, propone que se prohíban las universidades con fines de lucro;

- Se dice: "No podemos seguir indiferentes al devenir del orden colectivo, a la lucha heroica y al anhelo trascendente de libertad humana" (a pesar de lo cual no se mencionan las persecuciones y asesinatos contra estudiantes en Venezuela y Nicaragua)

- Se sostiene que aún existen comunidades que no tienen acceso a la educación y se insta a los gobiernos a ampliar la oferta educativa

- Se reivindica el valor de la multiculturalidad para terminar con las discriminaciones raciales y culturales; también se reclaman políticas para asegurar el acceso sin exclusiones de género o de cultura.

En el documento se enuncian también los resúmenes de los Ejes Temáticos que fueron discutidos en foros organizados previamente en toda América Latina. Se destacan estos temas.

- Se reafirma el papel estratégico de la educación superior en el desarrollo sostenible de América Latina y el Caribe. No se mencionan las experiencias que existen al respecto en la región y tampoco se indican las estrategias mediante las cuales las universidades pueden contribuir al desarrollo.

- La educación superior como parte del sistema educativo debe preocuparse por la formación de los docentes y por la calidad de la enseñanza en los otros niveles. Se afirma que la educación superior no asume cabalmente su compromiso sobre todo lo que se refierea la calidad de la formación de los docentes.

- Se sostiene que la internacionalización debe propugnar una cooperación interinstitucional basada en una relación solidaria entre iguales, con énfasis en la 
cooperación Sur-Sur y la integración regional. Nada se dice sobre el desmantelamiento del Mercosur Universitario durante la última década y el retroceso de los intercambios universitarios entre Argentina, Brasil, Paraguay y Uruguay.

- Se reivindica la función de integración cultural de las universidades apoyando la creación de programas interculturales y de inclusión de comunidades afroamericanas e indígenas en particular. El multiculturalismo y la defensa de las identidades culturales ha progresado mucho pero aún subsisten culturas discriminatorias que la educación superior tienen que ayudar a superar.

- Sobre la función social de las universidades se dice: De cara a tantos desafíos sociales que enfrenta la región, la educación debe construir su calidad y universalidad en el servicio a la comunidad local con miras al desarrollo humano... Aquí faltó señalar que existen muchas experiencias, públicas y privadas, para vincular a las universidades con las demandas sociales. Esto hubiera sido útil para marcar como efectos demostración los resultados de estos proyectos.

- En cuanto a la investigación científica y tecnológica y la innovación como motores del desarrollo se destaca la necesidad de producir conocimientos pertinentes para superar el modelo de desarrollo dominante y también para criticar la acumulación capitalista a través de las ciencias y las tecnologías. La propuesta se vuelve abstracta en tanto no se definan los modos de vinculación entre los centros de investigación, las universidades y las demandas sociales. Este punto, que es responsabilidad de las universidades latinoamericanas, es lo que permite un gran desaprovechamiento del capital intelectual de la región. 
- En cuanto a la vigencia de la Reforma Universitaria de 1918 se afirma: La actual coyuntura política en la región se expresa en algunos países, en la persecución de autoridades universitarias, en la violencia contra los estudiantes, en ajustes económicos y en la violación de la autonomía significa un retroceso histórico

Entre los párrafos que nos parecen más significativos encontramos estas preguntas y propósitos que plantea la Declaración de la CRES 2018: "? ¿Qué aportamos para la edificación de un orden justo, la igualdad social, la armonía entre las naciones y la impostergable emancipación humana?, como contribuimos a la superación del atraso científico y tecnológico de las estructuras productivas?....

... nuestras instituciones deben comprometerse activamente con la transformación social, cultural, política, artística, económica y tecnológica que es hoy imperiosa e indispensable.

Las instituciones de educación superior están llamadas a ocupar un papel preponderante en la promoción y fortalecimiento de las democracias latinoamericanas, rechazando las dictaduras y atropellos a las libertades públicas, a los derechos humanos y a toda forma de autoritarismo en la región"

Estas afirmaciones son congruentes con el grado de preocupación existente en las comunidades universitarias respecto a la responsabilidad social de las instituciones. Está emergiendo una nueva idea de la universidad como agente de desarrollo comprometida con las demandas de la sociedad, la economía y el Estado. Le faltó a la CRES 2018 destacar este nuevo enfoque estratégico.

La Reforma de 2018 jugó un rol importante en la formación de varias generaciones de dirigentes democráticos, reformistas y revolucionarios en A mérica 
Latina. Pero las universidades contribuyeron muy poco a la formación de especialistas en gestión pública durante las últimas décadas.

En la Declaración de la CRES2018 se menciona como una causa del atraso o de las amenazas al progreso a las injerencias del capital extranjero o de las empresasque quieren lucrar con el comercio de la educación.Personas de diferentes ideologías pueden compartir la reivindicación de la educación superior como bien público y como derecho social. Siendo coherentes con estos principios debería haber señalado la necesidad de fortalecer la gestión pública en todos los niveles. En varios de los países de la región (A rgentina, Brasil, M éxico, El Salvador ...) existe un alto grado de desorganización en el sistema estatal. Esta es una de las omisiones de la CRES2018.

Podemos señalar otras omisiones. Faltó un diagnóstico autocrítico sobre la función histórica y social de las universidades públicas en la región. No se reconoce que la mayoría de los dirigentes surgen de las universidades y que no hemos formado especialistas, profesionales y líderes adecuados para fortalecer los estados nacionales y crear un modelo de desarrollo sustentable, democrático e igualitario. Crear Estados inteligentes y eficientes para servir a la sociedad constituye una demanda urgente para las universidades.

En segundo lugar, se ha omitido el futuro. No se dice nada sobre la revolución que implica la virtualización de la enseñanza y la informatización de las organizaciones universitarias. No se dice nada sobre los programas de vinculación con empresas, organizaciones sociales y organismos del Estado que tienden a crear nuevos pactos entre la universidad y la sociedad. 
Se reivindica la autonomía, pero reiteradamente se pide la intervención del Estado y el apoyo de la sociedad para la auto-reproducción de las universidades. Pero en estos momentos el conjunto de las universidades latinoamericanas posee un capital intelectual enorme (cerca de 25 millones de estudiantes, unos 30 millones de graduados, 850.000 profesores universitarios, 500.000 investigadores) que no ha sido movilizado para crear un nuevo modelo de desarrollo. El capital intelectual se ha multiplicado un $200 \%$ en las tres últimas décadas, pero seguimos siendo pobres y subdesarrollados. El misterio está en el desaprovechamiento de nuestras capacidades educativas, científicas y técnicas.

El buen uso de la autonomía universitaria y la buena aplicación de los propósitos discursivos debiera llevarnos a proponer iniciativas para renovar las industrias, para mejorar los sistemas de salud, de justicia, de seguridad, para crear nuevos proyectos de urbanización y planeamiento territorial, para crear centros de excelencia en temas biotecnológicos, informáticos, ecológicos, económicos, de desarrollo social.

La CRES 2018 no definió las grandes líneas del futuro de las universidades de A mérica Latina y el Caribe. Pero existen en las universidades de la región suficientes experiencias para asumir nuevos modelos de organización, de prácticas pedagógicas, de programas de investigación o de proyectos de vinculación con la sociedad y el Estado. Faltó la mirada prospectiva y se recayó en las declaraciones ideológicas o conmemorativas.

De la Declaración final de la CRES 2018 no surge una crítica del modelo profesionalista, academicista y endogámico de las universidades de la región, que muchos especialistas han destacado durante las últimas décadas. Tampoco se 
advierte contra las tendencias burocratizadoras, corporativas o de control político que bloquean los cambios en las universidades públicas.

En la Fábula del parto en los monteslos montes dan terribles signos de estar a punto de dar a luz, infundiendo pánico a quienes los escuchan. Sin embargo, después de señales tan asombrosas, los montes paren un pequeño ratón. La expresión "el parto de los montes", se refiere a aquellos acontecimientos que se anuncian como algo mucho más grande o importante de lo que realmente terminan siendo.

Sería aventurado interpretar porqué ocurrió esto en estas notas marginales. Lo que es cierto es que lejos de presentar con lucidez el conjunto de desafíos a enfrentar y de las estrategias disponibles para construir el futuro la CRES2018 nos deja en la incertidumbre. Gestionar la incertidumbre para construir otro futuro y otro modelo de desarrollo inteligente y solidario sigue siendo la misión histórica de las universidades latinoamericanas. 